\title{
A função pedagógica da investigação da recepção teatral
}

\author{
Beatriz Ângela Vieira Cabral ${ }^{1}$ \\ Departamento de Artes Cênicas \\ CEART UDESC
}

Este projeto de pesquisa parte do pressuposto que a função pedagógica da investigação da recepção teatral está em identificar ou explicitar os fundamentos da cena ou dos demais objetos da pesquisa para o espectador. Para tanto propõe construir um questionário que funcione como uma cartografia do campo investigado.

Este procedimento tem contribuído, por um lado, para uma descrição etnográfica do processo de encenação; por outro lado, para ampliar o campo de percepção do espectador. Trata-se assim não de coletar informações sobre a recepção do espetáculo, o que tem sido extensivamente realizado por abordagens e autores distintos, mas de explicitar o que está sendo priorizado no processo de investigação cênica. Além disso, o foco na recepção, e não na avaliação, prioriza a percepção em vez de juízos de valor - a intenção é entender como o processo de construção da narrativa teatral está sendo interpretado.

Em pesquisa anterior ${ }^{2}$, um questionário foi usado como roteiro para entrevistar atores e espectadores de um espetáculo em comunidade. $\mathrm{O}$ objetivo foi delimitar o campo de investigação para os entrevistados, e coletar informações sobre os aspectos da montagem que foram mais significativos e tiveram maior repercussão. Uma vez que todos os aspectos mencionados no questionário haviam sido priorizados pela encenação, possíveis tendências para agradar ou criticar estariam sendo neutralizadas, e o entrevistado se concentraria em identificar o que lhe pareceu mais significativo. $\mathrm{O}$ resultado desta investigação surpreendeu em dois aspectos. Em primeiro lugar, não correspondeu às expectativas do pesquisador - aspectos do espetáculo priorizados pelos atores haviam sido previstos como aqueles que seriam priorizados pelo espectador comum (sem formação em teatro e com pouca experiência como espectador), e viceversa. Em segundo lugar, os atores, formandos de uma Licenciatura em Artes Cênicas, foram unânimes na constatação de que o questionário os fez perceber a extensão do

\footnotetext{
${ }^{1}$ Integrante do AQUIS - Núcleo de estudos sobre processos de criação artística .

${ }^{2}$ Análise da Recepção Vs. Avaliação do Espetáculo - implicações pedagógicas. CEART/UDESC.
} 
trabalho realizado, em termos da identificação e especificação dos elementos trabalhados.

A constatação de que a percepção do professor-diretor sobre os aspectos da montagem que despertariam maior interesse do elenco ${ }^{3}$ não se confirmou no levantamento de opiniões realizado através desta investigação, levou à experimentação do uso de questionários em contexto e circunstâncias diversas: Mostra de Teatro Educação, espetáculos de grupos profissionais, disciplinas de graduação, laboratórios experimentais, oficinas (vide anexo).

Em todas estas experiências a ampliação do entendimento dos participantes sobre o trabalho que acabaram de realizar foi considerado mais importante do que o resultado da pesquisa. As situações em que os questionários foram construídos em parceria (pesquisador e monitor, ou pesquisador e outros professores envolvidos na realização do curso ou oficina) potencializaram o planejamento das atividades, a identificação de objetivos e a explicitação de procedimentos.

Entre setembro de 2007 e junho de 2008 o foco de investigação se concentrou na recepção dos alunos e participantes das disciplinas de metodologia do ensino do teatro e das oficinas, também sobre metodologia, que ministro na UFSC.

Meu pressuposto é que sendo a formação do espectador uma questão central à formação do aluno de teatro é fundamental investigar como ela pode ser percebida e interpretada pelo professor. A complexidade da questão reside no fato de que a recepção tem relações estreitas com outras áreas do conhecimento, tais como ética, psicologia, sociologia e filosofia. A dificuldade está em sua associação com a avaliação, nesta o problema reside tanto em receber a crítica quanto em realizá-la.

O aspecto sensível que envolve a relação entre o artista e a crítica não se restringe ao teatro profissional - está presente na sala de aula, cada vez que é apresentada uma cena ou improvisação, e também na avaliação do aluno pelo professor, quer em disciplinas práticas ou teóricas. Existe uma similaridade entre as questões postas à formação do espectador e à avaliação do desempenho do aluno. Se neste caso o professor deve se perguntar 'o quê o aluno aprendeu e não se ele aprendeu o quê eu ensinei', no caso da formação do espectador a pergunta seria 'o que ele percebeu ou como ele leu a cena', e não se ele captou a intenção de sua produção. É interessante notar aqui, que pela perspectiva da recepção de uma obra de arte, esta questão está posta

\footnotetext{
${ }^{3}$ O elenco era constituído por formandos de Artes Cênicas contracenando com atores da comunidade sem experiência anterior em teatro.
} 
desde a década de 60; a priorização da intenção parece persistir apenas na área do ensino.

A aproximação das funções do professor e do diretor, na contemporaneidade, reforça a oportunidade de investigar a questão da recepção. Se no campo do ensino do teatro é crescente a ênfase na necessidade do professor assumir a função de diretor, no campo do teatro profissional aumenta a demanda de uma contrapartida aos apoios financeiros recebidos pelos grupos profissionais, em termos de oferecimento de oficinas e cursos para a comunidade. Assim sendo, uma forma de iniciar esta investigação é partir da constatação que o professor e o diretor são ambos mediadores entre a produção (da informação, da teoria, dos meios), e a recepção (por alunos e espectadores). Mas para que haja mediação é necessária uma concepção de ensino, do assunto tratado, do teatro e da encenação. É esta concepção que se pretende explicitar no questionário-base para a investigação.

A atual etapa da pesquisa está centrada na revisão bibliográfica, e, em especial em estudos sobre as perspectivas de Hans-Robert Jauss e Wofganf Iser. No primeiro caso, pretendo investigar, nos processos de análise da recepção de minhas disciplinas em andamento, a associação que Jauss fez entre as possibilidades que Gadamer atribuiu ao processo de entendimento de um texto (etapas da compreensão, interpretação e aplicação) e seu conceito de horizonte de expectativas. No segundo caso, pretendo aprofundar meu entendimento do conceito de "vazios do texto" (gaps), através dos quais Iser entende que se encontra a possibilidade do autor ter alguma possibilidade de 'programar' a leitura do mesmo. Para tanto, estou fazendo uma revisão das perspectivas históricas e teóricas da análise da recepção.

\section{Perspectivas teóricas}

Na esfera do espetáculo e da literatura, a recepção tem sido focalizada por diversas escolas filosóficas e métodos; entretanto, na área pedagógica esta função foi historicamente negligenciada. As razões variavam desde proteger as crianças de serem observadas até evitar seu possível exibicionismo.

Hoje é possível observar um crescente interesse pela recepção, como parte da tendência das ciências humanas de privilegiar a auto - reflexão e reconhecer a relevância do contexto. 
Em termos pedagógicos a atenção para com a recepção representa uma maneira segura para focalizar as repostas individuais em trabalhos de grupo: tanto pela confiabilidade de uma avaliação individualizada, quanto pela proteção que o foco na leitura da cena, ou situação, oferece ao envolvimento emocional do aluno com a ação dramática - se a comunicação não acontecer, isto não decorre da falta de talento, mas sim de uma falha na leitura do contexto e da cena.

O foco na recepção emergiu como uma reação contra o papel exclusivo do texto no processo de construção de significados em artes. Na década de 60 a teoria crítica e a prática educacional estavam sob a hegemonia dos "Novos Críticos", os quais alegavam que o significado de um texto estava estruturado dentro do próprio texto, e que qualquer influência quer da intenção do autor, quer da resposta do leitor poderiam apenas invalidar este significado. ${ }^{4} \mathrm{O}$ ponto convergente destas abordagens era a rejeição do autor e do leitor na interpretação - o texto em si era a base válida para isto. A "verdade" estava estruturada dentro do texto, quer este revelasse ou não as intenções do autor.

Os anos 70 testemunharam uma mudança na teoria crítica (e nas ciências humanas em geral) de uma ênfase na realidade externa e objetiva para o foco na resposta individual, e consequentemente, no relativismo. Esta inflexão na interpretação está apoiada nos modelos interativos de leitura da Psicologia Cognitiva, que representam o pensamento atual sobre a natureza do processo de leitura. De acordo com Harker “enquanto estes modelos variam amplamente quanto ao seu foco específico e a evidência empírica na qual se baseiam, eles compartilham um ponto de vista sobre o processo de leitura segundo o qual ambas as informações baseadas no texto e no leitorse relacionam interativamente para definir e aprofundar a influência de ambos na determinação do significado"(HARKER, 1992:33).

Apesar das diferenças entre seus métodos de investigação, argumenta Harker, as Teorias da Responsividade (Reader-Response Theories) e da Psicologia Cognitiva compartilham dois princípios que são particularmente importantes para a área da pedagogia do teatro:

1. ambas concebem o significado como resultante do engajamento ativo do leitor com o texto.

\footnotetext{
${ }^{4}$ O Novo Criticismo Americano enfatizou a autonomia do texto, negando tanto o autor quanto o leitor como considerações válidas na determinação dos significados literários. O Novo Criticismo dominou a teoria crítica e as práticas educacionais dos anos 30 aos 60.
} 
2. ambas afirmam que o entendimento ocorre no momento do engajamento do leitor com o texto, sem negar a importância de seus encontros prévios com o mesmo ou com outros textos.

Esta atenção para com a dimensão do leitor cresceu a partir dos anos 70, paralelamente ao reconhecimento do papel fundamental do contexto na produção e comunicação de significados.

Umberto Eco argumenta em The Limits of Interpretation (ECO, 1990:109), que ao selecionar convenções e signos e ao estabelecer relações co-textuais os atores estão lidando com ambigüidades e oferecendo toda uma série de conotações, isto é, sugerindo mais do que é realmente falado ou demonstrado. Uma vez que cada elemento no palco torna-se significante, o texto será sempre ideologicamente denso dado seu aspecto coletivo e multiplicidade de signos e convenções. O fato do texto teatral estar ancorado no movimento e na visualidade, às vezes a única forma através da qual as mensagens são codificadas, torna complexo o estabelecimento de um foco preciso.

Por outro lado, a leitura dos espectadores será sempre mediada pelo seu ângulo de visão, o qual os permite interpretar os signos verbais e visuais, e fazer inferências juntando as novas informações com seu conhecimento anterior. De acordo com Eco "o viés ideológico do leitor virá à tona, e irá ajudar a desnudar ou ignorar a estrutura ideológica do texto" (ECO, 1979:22).

Esta complexidade só pode ser superada porque a interpretação se baseia no contexto e suas circunstâncias históricas. Em A Theory of Semiotics (ECO, 1976) Eco distingue contexto (o ambiente onde uma dada expressão ocorre paralelamente a outras expressões pertencentes ao mesmo sistema sígnico) de circunstância (a situação externa onde a expressão ocorre).

Na vida cotidiana contexto e circunstâncias são usualmente implícitos - nós sabemos com quem estamos falando e a situação que estamos atravessando. Cada vez que encontramos estranhos em locais não usuais nós nos apresentamos e explicamos o que fazemos e de onde viemos.

No decorrer do processo dramático circunstâncias são as condições particulares da situação focalizada. Qualquer mudança ou desenvolvimento destas condições teria que levar em consideração o contexto no qual a situação acontece. Como se trata de um trabalho de ficção, o contexto é novo para os participantes. Daí a necessidade de especificá-lo a fim de que a situação se desenvolva de forma coletiva. A maioria dos 
desempenhos pobres em teatro se relaciona com a carência de informações sobre o contexto - as referências se esgotam, os alunos passam a se repetir, ou desistem de participar.

As interpretações individuais variam apesar da delimitação do contexto, circunstâncias e convenções presentes na cena; mas, elas dependam também não apenas do conhecimento que os espectadores possuem sobre a forma teatral e a temática apresentadas, mas também do gosto e experiência pessoais.

Assim sendo, um trabalho de grupo requer certa "negociação" em dois aspectos: 1. para assegurar que o texto coletivo considere as opções individuais - o que é basicamente uma estratégia democrática além de assegurar o desvendamento dos julgamentos de valor dos leitores;

2. para evitar a imposição de interpretação por parte tanto dos alunos quanto do professor - ao considerar diferentes leituras é improvável que seja tomada qualquer decisão final sem que sejam ouvidos os demais membros do grupo.

Uma abordagem centrada no leitor favorece a avaliação, pois implica uma relação dialógica entre professor/diretor e aluno, onde ambos trabalham juntos na busca pela melhor forma de expressão. A avaliação neste sentido não é uma tarefa individual, mas uma oportunidade para o aluno tentar ações e atitudes alternativas. A platéia figura como co-participante no processo de avaliação e poderá auxiliar a remover os 'pontos cegos' que podem limitar a percepção do espetáculo.

Neste sentido é possível dizer que a relação dialógica conduz a um modelo pedagógico que previne três problemas básicos da avaliação:

1. o costume de separar conhecimento e ação - o que leva a focalizar comportamentos em vez de conhecimento em artes. Por exemplo, facilidade para trabalhar em grupos, prontidão para a ação, etc.

2. o estabelecimento de expectativas - ao listar previamente os resultados esperados o professor está decidindo o quê os alunos deveriam fazer e pensar. Focalizar o leitor, ao contrário, permite desvendar contradições do esquema de avaliação e seus possíveis efeitos colaterais no ensino, favorecendo um relacionamento professor - aluno onde o argumento informa a prática.

3. a tentativa de remover 'juízos de valor' dos procedimentos de avaliação através do uso de registro fotográfico e filmagens para análise posterior. Esta alternativa, usualmente considerada 'neutra e objetiva' negligencia a dimensão temporal da 
atividade além de ser incapaz de considerar as circunstâncias contextuais. Por exemplo, um aluno usualmente com baixo desempenho poder ser avaliado melhor que seus colegas por reagir bem a este tipo de documentação.

As considerações acima deixam evidente que a interpretação não é neutra, ela reflete os valores operando no campo em que é realizada. Ao focalizar o leitor, privilegiando o espectador, os argumentos sobre valores antagônicos são abertos a todos os participantes no processo. Portanto, considerar a leitura e a interpretação como processos baseados em valores estéticos e políticos traz conseqüências importantes para a natureza da atividade, uma vez que não se pode mais alegar uma natureza a-histórica do conhecimento, nem contar mais com um modelo fixo a ser seguido para valorizar algo.

A dimensão da leitura na configuração da avaliação e da interpretação aponta para aquilo que tem sido considerado como papel produtivo do leitor. Produtivo no sentido de "leitura como construção" expressão cunhada por Tzvetan Todorov, como uma peculiaridade dos textos de ficção (TODOROV, 1980).

Pode-se dizer que em Teatro Educação a noção de leitura como construção tem um significado quase literal, pois é a função real dos leitores - participantes.

Em sua análise sobre o público teatral Susan Bennet acentua que "é no teatro de oposição pós - Brechtiano que a platéia atingiu um papel gradualmente mais produtivo" (BENNETT, 1990:21).

O teatro de Brecht se concentrou na mudança dos modos tradicionais de produção e recepção através da introdução daquilo que Elizabeth Wright chamou "recursos simbólicos planejados para interromper a unidade imaginária entre produtor e texto, ator e papel, espectador e palco, tais como: efeito de estranhamento, foco no gesto, apelo ao espectador" (WRIGHT, 1989:2).

A última fase de Brecht, por ele denominada "Teatro Dialético", enfatiza as contradições presentes nos sentimentos, opiniões, atitudes e interações humanas. Seu objetivo era promover a observação crítica e estimular a atividade na esfera social. De acordo com Benjamin, "seu esforço em tornar a audiência interessada no teatro como especialistas - não por razões culturais - é uma expressão de seu propósito político" (BENJAMIN, 1973:16).

Se as contradições estão no centro do engajamento ativo do espectador, este para ser eficaz depende da capacidade dos participantes decodificar o texto coletivo. Uma tarefa é oferecida ao espectador e este deve possuir ou obter as ferramentas para realizá- 
la. Este modo ativo de trabalhar o espectador para a função de decodificar convenções e signos se aproxima do desafio e do estímulo proporcionado por um jogo. "O prazer teatral é o prazer do signo", argumenta Anne Übersfeld, "é o mais semiótico de todos os prazeres" (...) Acima de tudo este prazer deriva da atividade; do envolvimento do espectador na interpretação de uma multiplicidade de signos. O objetivo não é encontrar a verdade, mas perceber que o mundo está lá para ser interpretado (ÜBERSFELD, 1982:127-135).

Segundo Susan Suleiman, a preocupação com o espectador e a interpretação representa também um sintoma da evolução recente das ciências humanas em direção à auto - reflexão e o reconhecimento da relevância do contexto. Suleiman analisa as principais abordagens teóricas voltadas à audiência, e enfatiza que sua combinação não deveria ser considerada de forma negativa, como ecletismo, mas positivamente, como necessidade (SULEIMAN, 1980: 3-45) 5

\section{Referências}

BENNETT, S. Theatre Audiences - A Theory of Production and Reception, London: Routledge, 1990.

BENJAMIN, W. Versuche uber Brecht. Frankfurt: Suhrkamp, 1981.

ECO, U. A Theory of Semiotics. Bloomington, Indiana University Press, 1976. . The Role of the Reader: Explorations in the Semiotics of Texts. Bloomington: Indiana University Press, 1979.

. The Limits of Interpretation. Bloomington: Indiana University Press, 1990.

HARKER, J. W. "Reader Response and Cognition: Is there a Mind in this Class?", In Journal of Aesthetic Education, 1992. Vol. 26, No, 3, pp 27-39.

ISER, W. The Implied Reader. Baltimore: John Hopkins UP, 1978. . The Act of Reading. Baltimore: John Hopkins UP, 1978.

JAUSS, H.R. Towards an Aesthetic of Reception. Minneapolis: University of Minnesota Press, 1982.

SULEIMAN, S. e CROSMAN, I. The Reader in the Text - Essays on Audience and Interpretation. New Jersey: Princeton University Press, 1980.

ÜBERSFELD, A. “The Pleasure of the Spectator”, in Modern Drama, 1982, Vol. 25 , no 1 , pp 127-139. 
WRIGHT, E. Post-Modern Brecht: a Re-Presentation. Londres: Routledge, 1989. 